\title{
Indoor Air Distribution of Nitrogen Dioxide and Ozone in Urban Hospitals
}

\author{
Hong-Wen Chen $\cdot$ Chun-Yu Chuang $\cdot$ \\ Heng-To Lin
}

Received: 19 March 2008/ Accepted: 2 January 2009

(C) Springer Science+Business Media, LLC 2009

\begin{abstract}
Indoor air pollution has recently become a public concern in Taiwan. People recognize that indoor air quality (IAQ) may be more important than outdoor air quality because they spend over $80 \%$ of their time indoors. IAQ could affect health and comfort of building occupants. The objectives of this study are (1) to characterize the indoor concentrations of selected air pollutants at two hospitals in Hsinchu, Taiwan, (2) to evaluate the potential indoor sources of pollutants in these selected hospitals and their indoor/outdoor relationships, and (3) to compare pollutant concentrations with values published in other studies. A significant between-hospital difference in average indoor concentration of nitrogen dioxide and 54.14, $32.69 \mathrm{ppb}$ for Hospital A and B, respectively $(p<0.05)$. Indoor nitrogen dioxide concentration was significantly positively correlated with outdoor nitrogen dioxide concentration, $\mathrm{PM}_{10}$ concentration, and traffic flow ( $r=0.91$, 0.65 and 0.72 , respectively). The ozone level was also lower in our hospitals than $30 \mathrm{ppb}$ standard.
\end{abstract}

Keywords Indoor air quality · Nitrogen dioxide . Ozone $\cdot$ Passive sampling

H.-W. Chen $(\bowtie) \cdot$ H.-T. Lin

Department of Environmental Engineering and Health,

Yuanpei University, 306 Yuanpei Street, 300 Hsinchu,

Taiwan, R.O.C

e-mail: hwchen@mail.ypu.edu.tw

C.-Y. Chuang

Department of Biomedical Engineering and Environmental

Sciences, National Tsing Hua University, 101, Section 2,

Kuang-Fu Road, 300 Hsinchu, Taiwan, R.O.C
Indoor air pollution has recently become a public concern in Taiwan. People recognize that indoor air quality (IAQ) may be more important than outdoor air quality because they spend over $80 \%$ of their time indoors (Spengler et al. 2001). IAQ (the content of interior air) could affect health and comfort of building occupants. The IAQ may be compromised by microbial contaminants (mold, bacteria), chemicals (such as nitrogen dioxide, ozone), allergens, or any mass or energy stressor that can induce health effects (Salthammer 1999). Recent findings have demonstrated that indoor air is often more polluted than outdoor air (albeit with different pollutants), although this has not changed the common understanding of air pollution (Guo et al. 2004). In fact, the health hazard of indoor air is often greater than that of the corresponding outdoor air. Therefore, IAQ has a greater public health effect. IAQ guidelines, issued by the Environmental Protection Agency of Taiwan in 2005 on the basis of pre-existing guidelines, deal with nine pollutants (Environmental Protection Agency 2005).

Owing to their toxicity, nitrogen dioxide $\left(\mathrm{NO}_{2}\right)$ and ozone $\left(\mathrm{O}_{3}\right)$ are the main indoor air pollutants mentioned in the guidelines. Nitrogen dioxide causes lung damage (i.e., morphological and physiological changes in pulmonary epithelium) and has genotoxic effects (Hayashi et al. 1987). $\mathrm{NO}_{2}$ and its derivatives (e.g., peroxynitrite) may induce DNA damage and mutagenesis by oxidizing DNA, deaminating DNA, and inducing the formation of $\mathrm{N}$-nitroso compounds (Chuang et al. 2003; Lin and Huang 2004; Noy et al. 1990). Ozone triggers a spectrum of effects that can result in respiratory toxicity. The inhalation of high concentrations of ozone is associated with fatal pulmonary edema (Jaffe 1967). Exposure to ozone can cause injury and inflammation (indicated by cellular and biochemical changes in the lung) (Devlin et al. 1991; Huffman et al. 
2001; Thurston and Ito 2001). These changes include increases in activity of lactate dehydrogenase, level of protein, and number of polymorphonuclear leukocytes in bronchoalveolar lavage fluid (Hatch et al. 1994).

Moreover, a significantly high coefficient of correlation ( $r$ ) was demonstrated between the number of hospitalized chronic obstructive pulmonary disease (COPD) patients and same-day levels of nitrogen dioxide (Fusco et al. 2001). Past studies have focused on outdoor rather than hospital indoor air. The objectives of this study are (1) to characterize the indoor concentrations of selected air pollutants at two hospitals in Hsinchu, Taiwan, (2) to evaluate the potential indoor sources of pollutants in these selected hospitals and their indoor/outdoor relationships, and (3) to compare pollutant concentrations with values published in other studies.

\section{Materials and Methods}

Sampling was conducted in two different hospitals in Hsinchu City. One of the selected hospitals is adjacent to a heavily traveled city thoroughfare, while the other is relative far from heavy traffic. The sampling period was 1 month (November, 2006). Samples were collected from the waiting rooms of the two hospitals. The air quality at each location was used to represent the air quality of that particular hospital. Two diffusive passive samplers were used to estimate indoor nitrogen dioxide and ozone levels. The design of the $\mathrm{NO}_{2}$ sampler was modified Lin's method (Lin and Huang 2004). The collected $\mathrm{NO}_{2}$ was quantified colorimetrically at $540 \mathrm{~nm}$ after using the Griess-Saltzman reaction at $25^{\circ} \mathrm{C}$ for $15 \mathrm{~min}$. The average recovery of the sampler was $95 \%$ (standard deviation, 5\%), accuracy was below $10 \%$, and detection limit was $2.0 \mathrm{ppb}$. The passive sampler for ozone was also modified Pehnec's method (Pehnec and Hršak 2003) and consisted of three rings and a wind screen. Nitrate is formed from the reaction of nitrite ion and ozone. After the sampling, filters were sonicated for $15 \mathrm{~min}$ in $15 \mathrm{~mL}$ of water and then centrifuged for $10 \mathrm{~min}$. The nitrate ion was analyzed using a ion chromatograph. Anions were separated on an analytical column and a guard column, with $3.5 \mathrm{mM} \mathrm{Na} \mathrm{Na}_{3} / 1.0 \mathrm{mM}$ $\mathrm{NaHCO}_{3}$ mixture as an eluent, and their concentrations were monitored using a conductivity detector (Pehnec and Hršak 2003; Zhou and Smith 1997). The ozone concentration was calculated from the nitrate concentration. The limit of detection (LOD) of the $\mathrm{O}_{3}$ passive sampler was $2.0 \mathrm{ppb}$ and recovery was above $90 \%$.

Mann-Whitney $U$ test was used to compare the average levels of indoor air and indoor/outdoor ratio for $\mathrm{NO}_{2}$ and $\mathrm{O}_{3}$ between two hospitals. A multiple regression was performed to assess the relationship between the $\mathrm{NO}_{2}$ and $\mathrm{O}_{3}$ levels of hospital indoor air and possible effect variables. The data analysis was performed using SPSS 11.0 for Windows. The criterion for significance was set at $p<0.05$.

\section{Results and Discussion}

Figure 1 shows a significant between-hospital difference in indoor concentration and average indoor concentration of nitrogen dioxide (12.30-75.30, and $9.62-48.80 \mathrm{ppb}$ for Hospital A and B, respectively, and 54.14 and $32.69 \mathrm{ppb}$ for Hospital A and B, respectively; $p<0.05$ ). The range of ozone concentration and average ozone concentration paralleled those of nitrogen dioxide (15.00 and $9.70 \mathrm{ppb}$ for Hospital A and B, respectively). The finding that the between-hospital relationship for nitrogen dioxide concentration was similar to that for ozone concentration suggests the two contaminants may have come from outside exhaust fumes. Furthermore, cyclical trend analysis showed that the concentrations of these contaminants inside the hospitals was highest on Monday when the traffic flow was highest in the weekly cycle and was lowest on weekends and holidays, when the traffic flow was lowest. This pattern was especially evident in Hospital A, which was adjacent to a major road. This result is comparable to that of Guo et al. (2004), who found the indoor air quality of markets in Hong Kong was affected by heavy local traffic.

To detect the sources of nitrogen dioxide and ozone inside the hospitals, this research conducted multivariable correlation analysis and an analysis of the ratio of indoor concentration to outdoor air concentration. Table 1 shows the relationships between nitrogen dioxide and ozone concentrations and the variables that influence them. Indoor $\mathrm{NO}_{2}$ concentration was significantly positively

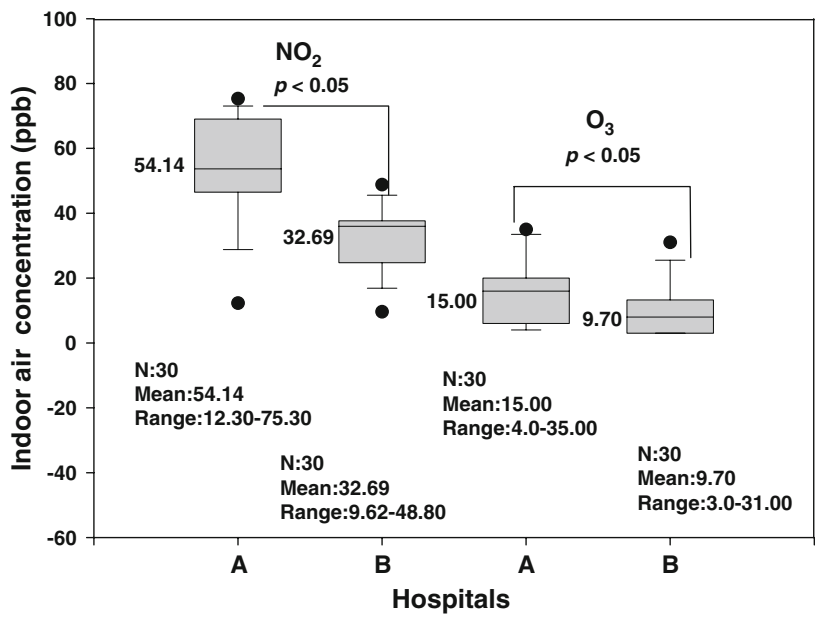

Fig. 1 Distribution of nitrogen dioxide and ozone levels at two hospitals 
Table 1 Correlation analysis of selected variables affecting nitrogen dioxide and ozone levels of hospital indoor air

Note: $N S$ is not statistically significant $(p>0.05)$

\begin{tabular}{|c|c|c|c|c|}
\hline \multirow[t]{2}{*}{ Variables } & \multicolumn{2}{|l|}{ Indoor $\mathrm{NO}_{2}$} & \multicolumn{2}{|l|}{ Indoor $\mathrm{O}_{3}$} \\
\hline & $\begin{array}{l}\text { Correlation } \\
\text { coefficient }(r)\end{array}$ & $p$ value & $\begin{array}{l}\text { Correlation } \\
\text { coefficient }(r)\end{array}$ & $p$ value \\
\hline \multicolumn{5}{|l|}{ Outdoor variables } \\
\hline $\mathrm{NO}_{2}$ & 0.91 & $<0.05$ & 0.29 & NS \\
\hline $\mathrm{O}_{3}$ & 0.32 & NS & 0.89 & $<0.05$ \\
\hline $\mathrm{PM}_{10}$ & 0.65 & $<0.05$ & 0.38 & NS \\
\hline Traffic flow & 0.72 & $<0.05$ & 0.41 & NS \\
\hline Rainfall & -0.32 & NS & -0.28 & NS \\
\hline Wind speed & -0.22 & NS & -0.36 & NS \\
\hline Temperature & 0.21 & NS & -0.12 & NS \\
\hline Distance to the road & -0.58 & $<0.05$ & -0.40 & NS \\
\hline \multicolumn{5}{|l|}{ Indoor variables } \\
\hline Temperature & 0.18 & NS & 0.12 & NS \\
\hline Ventilation rate & 0.71 & $<0.05$ & 0.69 & $<0.05$ \\
\hline Patient number & 0.29 & NS & 0.32 & NS \\
\hline
\end{tabular}

apparent between-hospital difference in I/O ratios, indicating that ventilation rate is another important factor. Since the ventilation rate was higher in Hospital A, which was close to a major road with heavy traffic, than in Hospital B, the two hospitals had similar I/O ratios. Hospital B had a lower ventilation rate, which increased its I/O ratio. Ozone concentration ranges paralleled nitrogen dioxide ranges in the two hospitals ( $\mathrm{I} / \mathrm{O}$ average ratios, 0.33 and 0.26 for Hospital A and B, respectively). The lower I/O ratios for ozone than for $\mathrm{NO}_{2}$ indicated that ozone was not affected by traffic flow and weather. This result is consistent with that of the correlation analysis in Table 1.

Table 2 shows indoor air levels of $\mathrm{NO}_{2}$ and $\mathrm{O}_{3}$ reported in several countries. The $\mathrm{NO}_{2}$ levels in our two hospitals were 54.14 and $32.69 \mathrm{ppb}$, respectively, which is higher than that detected in bedrooms in Gallelli, Italy (13.2 ppb) and Spengler, USA (27.2 ppb) and lower than that detected in ice rinks in Pennanen, Finland (176.5 ppb) (Gallelli et al. 2002; Pennanen et al. 1998; Spengler et al. 1994). Shiau (1987) found similar levels of $\mathrm{NO}_{2}$ in ordinary living rooms in Taiwan $(50 \mathrm{ppb})$. Taiwan does not yet have a regulatory standard for indoor $\mathrm{NO}_{2}$ concentration. However, $\mathrm{NO}_{2}$ level in our two hospitals was lower than $250 \mathrm{ppb}$ (the standard of indoor air quality set by the US EPA). The $\mathrm{O}_{3}$ level in our two hospitals (15.0 and $\left.9.7 \mathrm{ppb}\right)$ was lower than in ordinary living rooms (50 ppb) (Jakobi and Farian 1997) and office buildings (45 ppb) (Weschler and Shields 1994). The $\mathrm{O}_{3}$ level was also lower in our hospitals than the standard value $(30 \mathrm{ppb})$ set by the Taiwan EPA. Although the air quality of our two hospitals varied as a result of such factors as outdoor pollution, ventilation rate, etc., overall, both the $\mathrm{NO}_{2}$ and $\mathrm{O}_{3}$ levels were within the limits set by standard regulations. Also, these factors have not been shown to pose health threats to

Fig. 2 Average ratio of indoor/outdoor concentration for nitrogen dioxide and ozone at two hospitals 
Table 2 Nitrogen dioxide and ozone levels in indoor air

\begin{tabular}{lllcl}
\hline Compounds & Country & Sampling site & Concentration $(\mathrm{ppb})$ & Reference \\
\hline $\mathrm{NO}_{2}$ & Italy & Bedroom & 13.2 & Gallelli et al. (2002) \\
& USA & Bedroom & 27.2 & Spengler et al. (1994) \\
& Finland & Ice rink & 176.5 & Pennanen et al. (1998) \\
& Taiwan & Living room & 56.1 & Shiau (1987) \\
& Taiwan & Hospital A & 54.1 & This study \\
& Taiwan & Hospital B & 32.1 & This study \\
$\mathrm{O}_{3}$ & Germany & Living room & 50.0 & Jakobi and Farian (1997) \\
& USA & Office & 45.0 & Weschler and Shields (1994) \\
& Taiwan & Hospital A & 15.0 & This study \\
& Taiwan & Hospital B & 9.7 & This study \\
\hline
\end{tabular}

patients in the hospitals. Nonetheless, indoor air quality of hospitals should be continually monitored and individual exposure evaluated to ensure public health. Good ventilation in hospital should be encouraged to maintain indoor air quality. Up to now, no regulatory standard for indoor $\mathrm{NO}_{2}$ level has been set in Taiwan because so few studies have been done. The results will provide a local data to help revise the indoor air quality regulations issued by the relative agencies. As our study was conducted over a period of one month only, the data we collected may be limited in terms of temporal generality, and for a further project, we need to cover a longer time, in order to collect adequate information and data to make to accurately evaluate indoor air quality and health risk in hospital.

Acknowledgments We thank the National Science Council of the Republic of China, Taiwan, for financially supporting a part of this research under Contract No. NSC 95-2815-C-264-008-B.

\section{References}

Chuang CY, Hung JC, Yang CY, Ma YC, Sung FC (2003) Plasma nitrogen oxides levels in taxi drivers and community residents. Bull Environ Contam Toxicol 70:430-436. doi:10.1007/s00128003-0004-6

Devlin RB, McDonnell WF, Mann R, Becker S, House DE, Schreinemachers D, Koren HS (1991) Exposure of humans to ambient levels of ozone for 6.6 hours causes cellular and biochemical changes in the lung. American J Respir Cell Mol Biol 4:72-81

Environmental Protection Agency (2005) Guideline notes for management of indoor air quality in offices and public places, Taiwan

Fusco D, Forastiere F, Michelozzi P, Spadea T, Ostro B, Arca M, Perucci CA (2001) Air pollution and hospital admissions for respiratory conditions in Rome, Italy. European Respir J 17:1143-1150. doi:10.1183/09031936.01.00005501

Gallelli G, Orlando P, Perdelli F, Panatto D (2002) Factors affecting individual exposure to $\mathrm{NO}_{2}$ in Genoa (northern Italy). Sci Total Environ 287:31-36. doi:10.1016/S0048-9697(01)00990-1

Guo H, Lee SC, Chan LY (2004) Indoor air quality investigation at airconditioned and non-airconditioned markets in Hong Kong. Sci Total Environ 323:87-98. doi:10.1016/j.scitotenv.2003.09.031
Hatch GE, Slade R, Harris LP, McDonnell WF, Devlin RB, Koren HS, Costa DL, McKee J (1994) Ozone dose and effect in humans and rats. American J Respir Crit Care Med 150:676-683

Hayashi Y, Kohno T, Ohwada H (1987) Morphological effects of nitrogen dioxides on rat lung. Environ Health Perspect 73:135-145. doi: $10.2307 / 3430604$

Huffman LJ, Judy D, Brumbaugh K, Frazer DG, Reynolds JS, McKinney WG, Goldsmith WT (2001) Hyperthyroidism increases the risk of ozone-induced lung toxicity in rats. Toxicol Appl Pharm 173:18-26. doi:10.1006/taap.2001.9174

Jaffe LS (1967) The biological effects of ozone on man and animals. American Ind Hyg Assoc J 28:267-277

Jakobi G, Farian P (1997) Indoor/outdoor concentration of ozone and peroxyacetyl nitrate. Int Biometeorol 40:162-165. doi:10.1007/ s004840050037

Lin TS, Huang YL (2004) Elevated exposure to nitrogen dioxide during food preparation: results from a cooking laboratory. Bull Environ Contam Toxicol 72:535-541. doi:10.1007/s00128-004-0277-4

Noy D, Brunekreef B, Boleij JSM, Houthuijs D, De Koning R (1990) The assessment of personal exposure to nitrogen dioxide in epidemiological studies. Atoms Eviron 24:2903-2909

Pehnec G, Hršak VV (2003) Comparison of active and passive measurement of ozone in Zagreb air. Bull Environ Contam Toxicol 70:343-350. doi:10.1007/s00128-002-0197-0

Pennanen AS, Vahteristo M, Salonen RO (1998) Contribution of technical and operational factors to nitrogen dioxide concentration in indoor ice arenas. Environ Int 24:381-388. doi:10.1016/ S0160-4120(98)00018-X

Salthammer T (1999) Organic indoor air pollutants - occurrence, measurement evaluation. Wiley, Germany

Shiau SJ (1987) The development and application of a diffusive sampler for nitrogen dioxide. Masters Thesis. Institute of Public Health, National Taiwan University, Taipei

Spengler J, Schwab M, Ryan PB, Colome S, Wilson AL, Billick I, Becker E (1994) Personal exposure to nitrogen dioxide in the Los Angeles Basin. Air Waste 44:39-47

Spengler JD, Samet JM, McCarthy JF (2001) Indoor air quality handbook. McGraw-Hill, New York

Thurston GD, Ito K (2001) Epidemiological studies of acute ozone exposure and mortality. J Expo Sci Env Epid 11:286-294. doi: 10.1038/sj.jea.7500169

Weschler C, Shields H (1994) Indoor chemistry involving $\mathrm{O}_{3}$, NO, and $\mathrm{NO}_{2}$ as evidenced by 14 months of measurement at a site in southern California. Environ Sci Technol 28:2120-2132. doi: 10.1021/es00061a021

Zhou J, Smith S (1997) Measurement of ozone concentration in ambient air using a badge type passive monitor. J Air Waste Manage Assoc 47:697-703 